\title{
Prevention in primary care - intrafamilial predictive model (IPM)
}

\author{
Valeria Herdea ${ }^{1,9,10}$, Raluca Ghionaru ${ }^{1,9}$, Emiliana Costiug 2,9, Ileana Brinza ${ }^{5,9}$, \\ S.N. Rus ${ }^{3,9}$, L. Comnea ${ }^{1,9}$, E. Egri, ${ }^{4,9}$, E. Ruja2,6,9, Liliana Chitanu ${ }^{5,9}$, C.F. Pop ${ }^{2,6,9}$, \\ L. Soldea ${ }^{8,9}$, A. Herdea ${ }^{7,9}$, P. Tarciuc ${ }^{1,9,10}$ \\ ${ }^{1}$ Family medicine-pediatric profile, Bucharest, Romania \\ ${ }^{2}$ Family medicine-pediatric profile, Cluj Napoca, Romania \\ ${ }^{3}$ Family medicine-pediatric profile, Bistrita, Romania \\ ${ }^{4}$ Family medicine-pediatric profile, Sibiu, Romania \\ ${ }^{5}$ Family medicine, Braila, Romania \\ 6"Iuliu Hatieganu" University of Medicine and Pharmacy, Cluj-Napoca, Romania \\ 7"Grigore Alexandrescu" Emergency Children Hospital, Bucharest, Romania \\ ${ }^{8}$ Diabet, nutrition and metabolism specialist, Bucharest, Romania \\ ${ }^{9}$ Romanian Association for Pediatric Education în Family Medicine (AREPMF) \\ ${ }^{10}$ UMFST, Tg Mures, Romania
}

\begin{abstract}
The essence of the family medicine specialty remains surveillance of the health for the whole family: from pregnancy to child, from young to senior, from health to disease, from preventive to therapeutical interventions. The family doctor (GP) carries on two or even three generations of the same family, comes în contact with each family member, during many years of medical practice. The continuous clinical monitoring, will allow preparation of a "Risk Factors Map" (RFM). RFM is based on the high risk chronical pathology faced by a family over generations. Analising RFM and identifying major risk factors that act inside the family, GP can generate an intrafamilial predictive model (IPM). Having under medical care the whole family, developing în time a relationship of trust with the patients, based on serious profesional training, armed with good communication skils, GP has the possibility to implement personalized educational interventions inside the family for life style changing. This kind of intervention applied în early childhood, can slow down or delay the appearance and the evolution of the severe chronical diseases. În essence, IPM is an early preventive interventional mechanism în controlling the occurrence of major chronic diseases în future adults.
\end{abstract}

Keywords: predictive model, obesity, hypertension, risk factors, chronic diseases, education for health

\section{BACKGROUND}

According to WHO data (2018), chronic noncommunicable diseases are a top priority: obesity, hypertension, dyslipidaemia, diabetes mellitus and cancer, with high morbidity and mortality, especially through severe co-morbidities, with reserved prognosis. They associate sufference, disability, high rate of death, and last but not least, the burden of socio-economic costs it generates.

In 2017, the WHO publishes Guideline Assessing and managing children at primary health care facilities to prevent overweight and obesity in the context of the double burden of malnutrition, a document that brought medical attention to the double burden of malnutrition, both through the weight- encountered in severe forms, especially in subsaharian countries, but also in overweight, expanded in almost all countries of the world at alarming levels (1). Obesity remains one of the major risk factors involved in the emergence and development of chronic non-communicable diseases, especially when this factor acts during childhood. 
According to $\mathrm{WHO}$, malnutrition includes micronutrients deficiency, micronutrients excess, obesity, diet-related diseases, the basis of future chronic diseases (1). Gobally: 52 million children under 5 are undernourished, 41 million are obese, $45 \%$ of deaths in children under 5 years of age are related to malnutrition (1).

At international level, the prevalence of obesity increased more than twice between 1980 and 2014, (WHO)- Position paper on the European Obesity Day (2).

Most of the world's population lives in countries where overweight and obesity kill more people than underweight $(3,4,5)$.

In Romania, in 2007 official data showed $7 \%$ of obesity among adolescents $10-18$ years, $2014-16 \%$, so that in 2016, we would have a percentage of $24.5 \%$ of children aged 5-19 years suffering from of obesity $(2,4,9)$.

In Romania, in urban area, in $1999-15 \%$ of school-age children were in the overweight category, 10 years later - 2009- $25 \%$ of children were in the overweight / obese category.

The family doctor carries out family care, monitoring the evolution of her members, horizontally and longitudinally throughout they lifes. Monitoring allows development of a "risk map" (HFR), based on the pathology of that family. The timely development of a trust-based relationship with patients, with a very good professional training and optimal communication skills, allow the GP, to apply in practice, personalized educational interventions adapted to patient profile. Counseling the patient to understand the importance of adopting a healthy lifestyle, the need to actively engage in maintaining his / her own health, starting from the realities of his / her family pathology, we can obtain very good results, especially when efforts are made at the level of the family group and not limited to only one of the members of that family.

\section{AIMS}

Introduction of intra-familial predictive model (IPM) like preventive interventional mechanism applicable from early childhood could reduce the incidence of major chronic diseases in future adult

\section{OBJECTIVES}

Main objective - Reducing the incidence of chronic diseases with a major impact on the health of the adult future.

\section{Specific objectives}

1. Evaluation of risk factors with major impact on the monitored community/family

2. Intra-Family Risk Assessment (Intra-Family Risk Map)

3. Intra-familial Predictive Model (IPM)

4. Family Preventive Interventions (Principles)

\section{MATERIAL AND METHOD}

The prospective observational study was conducted in an urban community within two family medicine practices.

Conditions for inclusion in study:

- patient monitored in praxis for minimum 5 years before starting the study,

- at least two generations of the same family, monitored in the last 5 years, in the medical offices (parents-children),

- parent's presence in the office for the time of consultation,

- the informed consent of the parent,

- compliance with the hygienic-dietary recommendations received from medical staff.

- BMI> 25

Exclusion conditions: Absence of the above criteria

36 children aged 6-18 years, sex ratio 2: 1 (F: M) were evaluated over 6 months. The observation was based on personal physiological case history, personal pathological history, heredo-collateral history of the child, anamnesis, clinical examination, over three visits in the medical office. The medical records were taken from the patient's medical records, office informatical program, supplemented with data from the patient's parents All these data help the health care providers (HCP) identifying family risk factors presence and chronical diseases over generations.

The children were clinically examined three times during this period of 6 months: October (Visit 1), january (Visit 2) and april (Visit 3). Clinical parameters: weight $(\mathrm{G})$, height $(\mathrm{H})$, blood pressure (TA), body-mass index (BMI), were recorded at each visit.

Parents and child received recommendations in basic, clear language, coresponding to the understanding level:

1. Diet counseling: reduction for animal fat, salt, sugar, preservatives, food coloring, canning, energizing carbohydrate drinks, alcohol, addictions.

- Balanced diet recommendations: proteins / carbohydrates / lipids / caloric intake, correspond- 
ing to age and health status, divided in 3 meals per day and adequate fluid consumption.

Every meals were designed to contain:

- protein - cheese or white meat or egg 100-150 $\mathrm{g}$ (depending on age, weight of the child), raw vegetables salad, whole grain dietary biscuits, 1 aftermeal apple

The parent were advised on the recommended diet for the child: fresh, varied, giving the child the possibility of choice from a list, attitude which facilitated adherence to the maintenance of the regime.

2. Generaly healthy lifestyle counseling:

- outdoor exercise minimum 60 minutes daily, time spent together parent- child.

- at least 1 daily meal with the whole family,

- participation and involvement in the child's life,

- attitude of encouraging and stimulating the creative qualities of the child,

- awareness of the benefits of weight reduction and risks in the medium and long term as a result of overweight,

- encouraging the perception of child's correct self image,

- avoiding "consolation tables" or stressed atmosphere during meals,

- diet keeped by the hole family, according to the possibilities connected to health condition and co-morbidities present to the family members

- specialized psychotherapy on loss, mourning reaction, education to adapt to stressful environmental conditions, counseling for acceptance in the school environment.
For the interpretation of medical data, nomograms of WHO, CDC, CDT Babeş, INSP were used $(6,7,8,11)$.

In the educational process were involved: the child's family, the child, the nurse and the MD, the nutritionist, the orthopedic physician (in cases involving children with vertebral static disorder), who also needed counseling for professional reorientation -6 children of 36 ), the psychologist. Health education focused on the development of a healthy lifestyle: correct nutrition, varied, adapted to the needs of age growth, sport and outdoor movement, balanced, warm, supportive family environment, education to prevent infectious diseases by immunization, professional orientation.

\section{RESULTS}

During the visits, clinical parameters were recorded:

\section{Weight}

Children included in the study were weighed using the same type of scale, taliometer, blood pressure measuring device (Fig. 1, 2).

We notice a $8.7 \%$ weight loss (limits: $1 \%-13 \%$ of initial weight) at Visit 3 to Visit 1.

There were notable differences between children on the weight in kilograms $(\mathrm{kg})$ lost during the 6 months. The weight loss was influenced by the age of the child in question, the support he had in the family environment. Optimal results were recorded in families where all family members maintained a child-like diet throughout the 6 months and the child also benefited from emotional support -

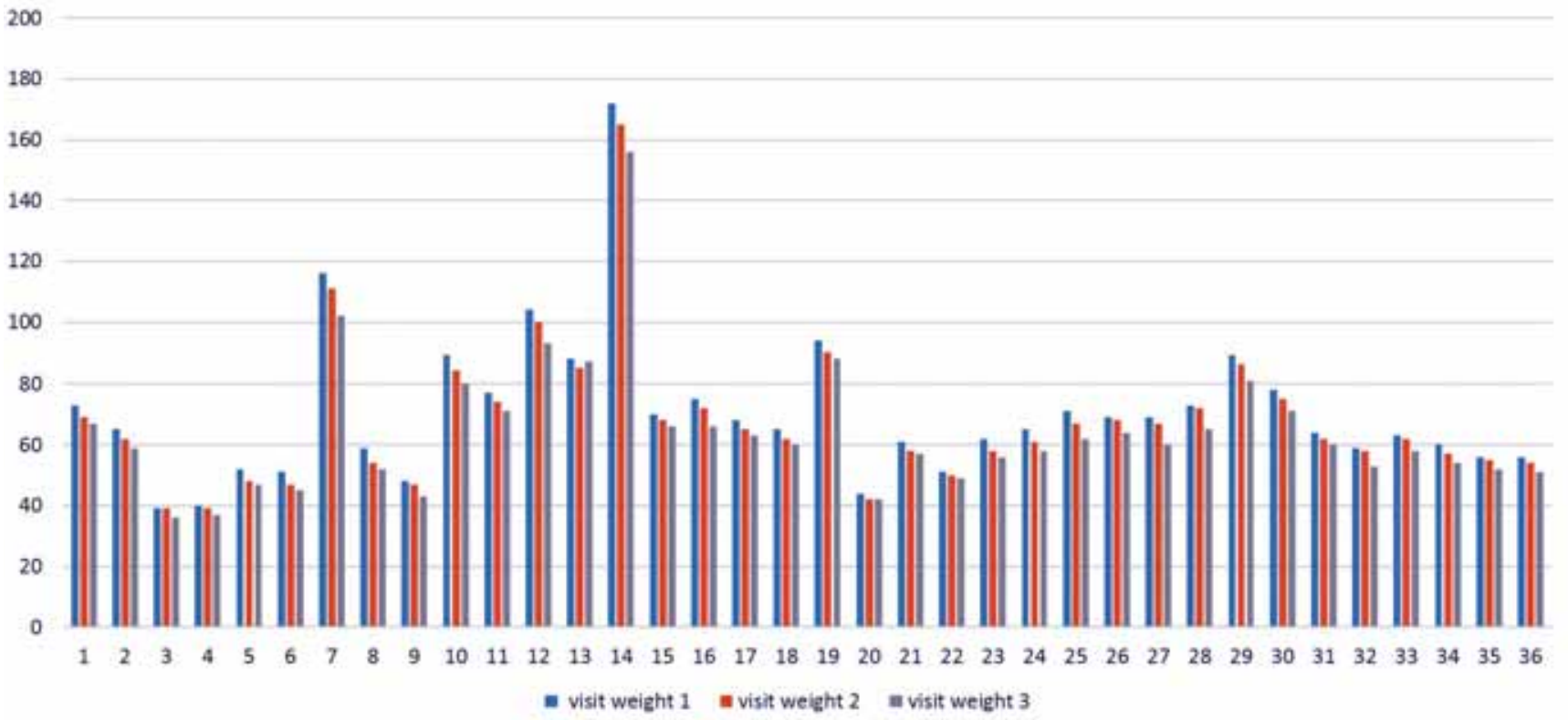

FIGURE 1. Evolution of the weighted curve 


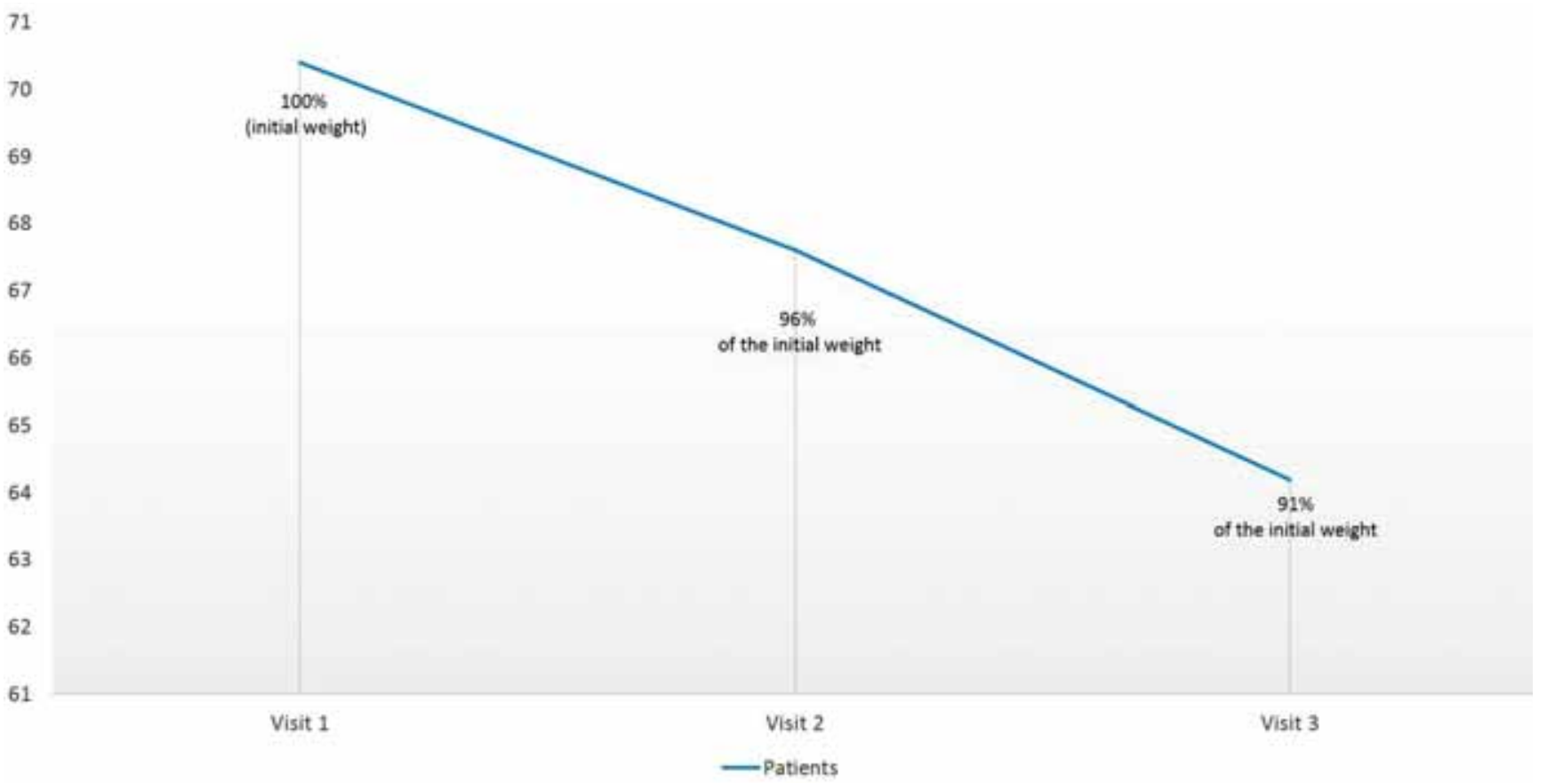

FIGURE 2. Comparison of weight average over the 6 months

the parent spent more time together, appropriate to the child's expectations.

Another clinical parameter recorded was the height of the children. Between 6 and 18 years, the increase in height is accelerated. It is advisable to correlate the height, weight, age $(6,7,8)$.

For certain special situations, healthcare professionals can only provide counseling and support work: special intra-familial stressful conditions, socio-economic family conditions, counseling in case of loss of a close relative. Many of these situations are trigger factors for rapid weight gain for children, especially if exist a susceptibility. Obesity through the mechanism of intake is often identified as a way to suppress for a child who is crossing stressful events for long period (more than 6-12 months, constantly).

\section{BMI-body-mass index}

The calculation and interpretations were made in accordance with the National Heart, Lung and Blood Institute (USA) (12) (Fig. 3, 4).

BMI values used for interpretation:

BMI $<25$ - healthy

BMI > 25-29.9-overweight

60

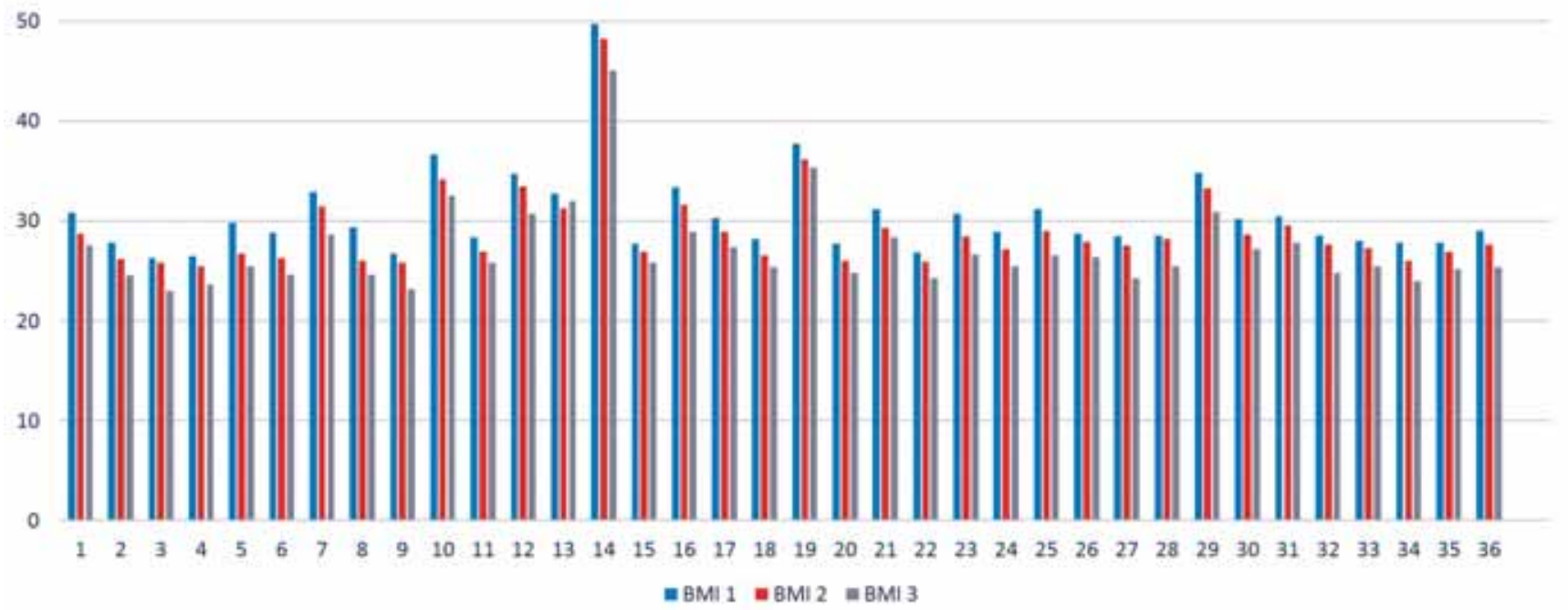

FIGURE 3. BMI Evolution (Body-mass index) 


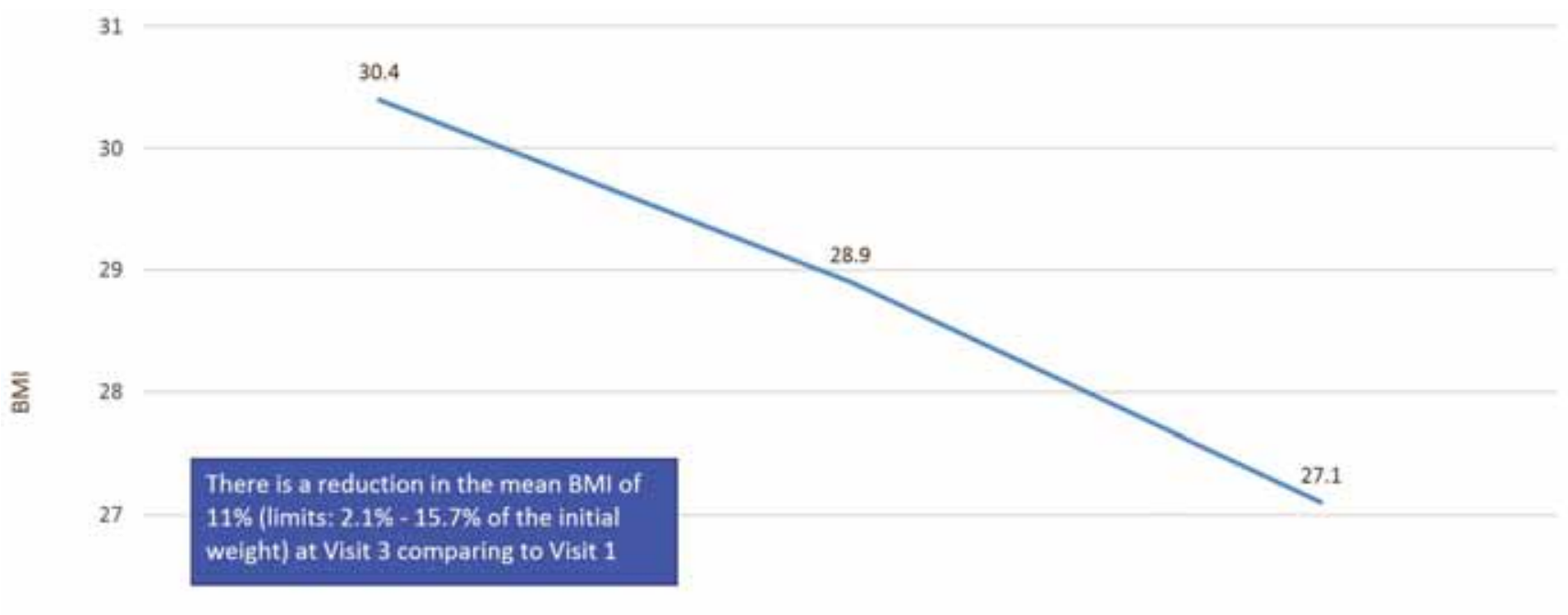

26

\begin{tabular}{c|c|c|c|}
\multicolumn{1}{c|}{25} & Visit 1 & Visit 2 & Visit 3 \\
\cline { 2 - 5 } & 30.4 & 28.9 & 27.1
\end{tabular}

FIGURE 4. The average BMI evolution over the 6 months

BMI $>30.0-34.9$ obesity gr I

BMI $>35.0-39.9$ obesity

BMI $>40.0$ obesity gr III

There is a reduction in the mean of BMI of $11 \%$ (limits: $2.1 \%-15.7 \%$ by weight between visit I and visit 3).

Extreme BMI values have been reported in children from families struggling with chronic diseases: HBP, dyslipidemia, diabetes, osteo-articular dynamics disorders, cancer, neuropsychiatric disorders, risk factors being mixed - determinants- geneticists and predisposing factors (inadequate diet, lack of movement, trauma, difficult adaptation to the environment).

\section{Blood pressure}

The high blood pressure (HBP) observed in children showed a direct correlation with the stressful intrafamilial environment. HTA in adolescents with obesity en I-III, limited or absent sports activity, energizers consumption and smoking, transform the condition from functional (eg "white coat HBP") into organic (subjectively perceived by fa-

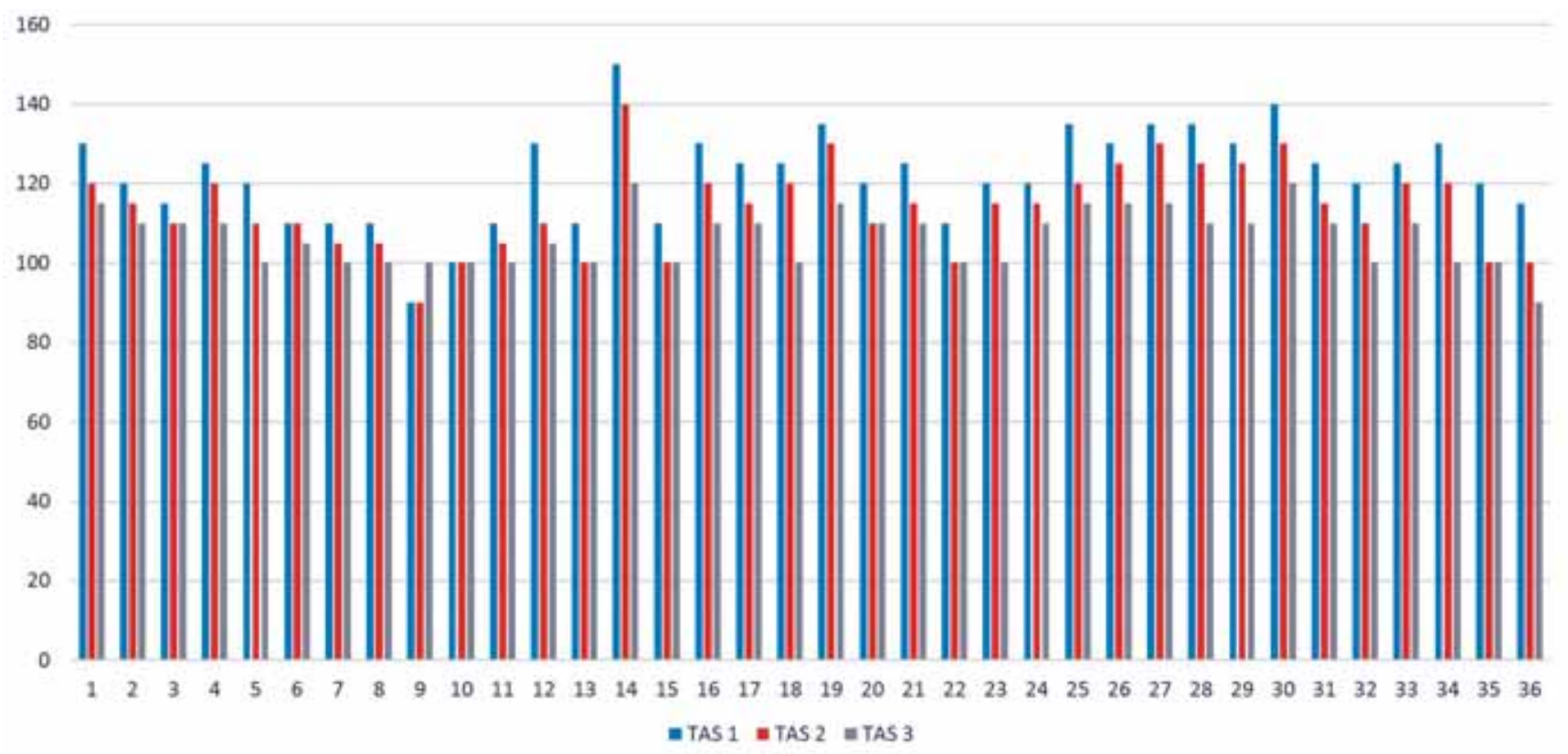

FIGURE 5. Evolution of systolic blood pressure (TAS) 


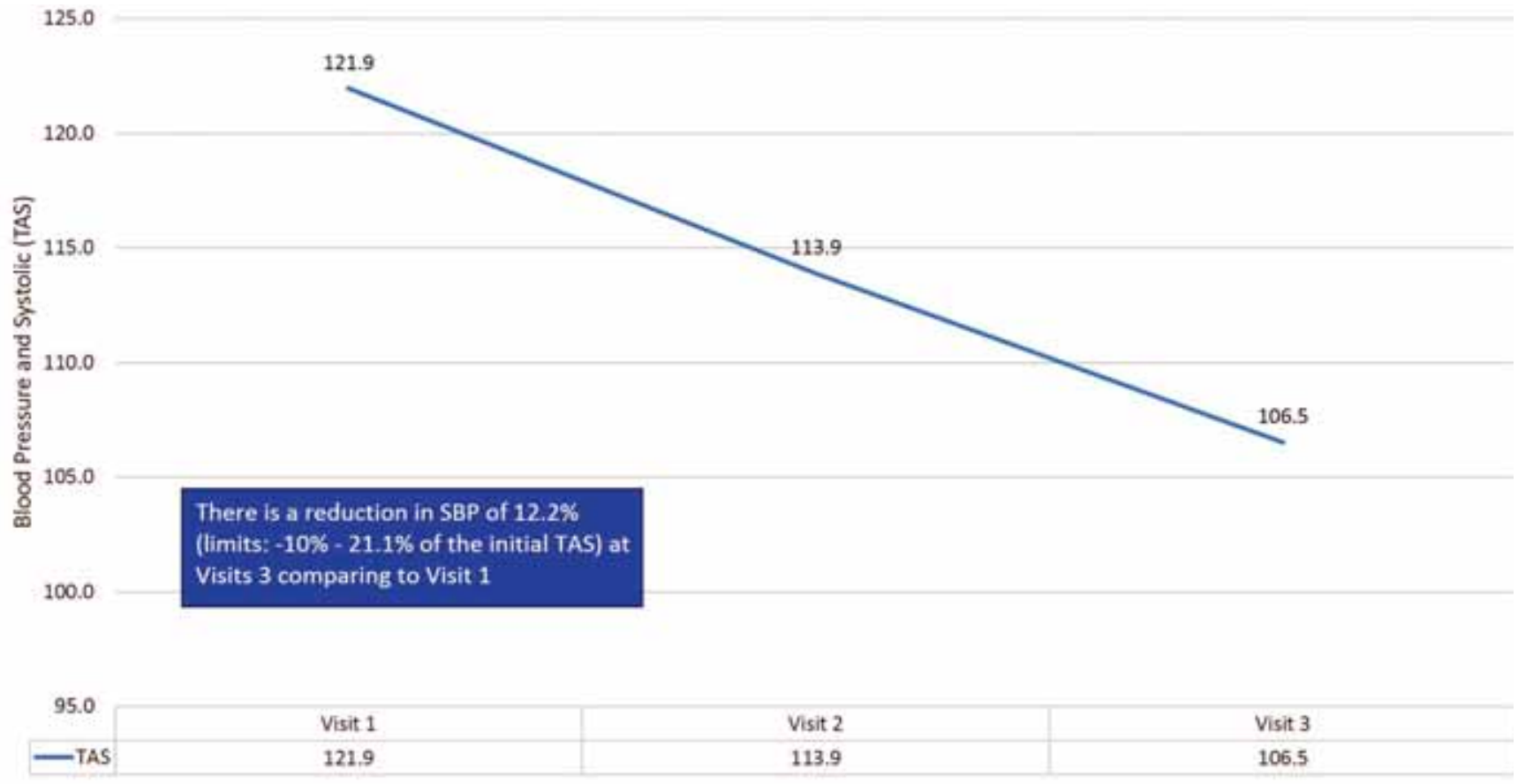

FIGURE 6. The average evolution of systolic blood pressure over the 6 months

tigue at low effort, dyspnea and objective through recording thickening of the left ventricle wall on the echocardiographic exam) (Fig. 5, 6).

During the 6 months, there was a decrease in SBP (Systolic Blood Pressure) values averaging 15 $\mathrm{mm} \mathrm{Hg}$ in girls and $10 \mathrm{mmHg}$ in boys, with wide variations, related to two aspects:

1. The intrafamilial predisposition to obesity, to complicated hypertensive disease - In these families, children who are over- weight or obese will have HBP'
2. The "white coat" HBP - the pattern signaled on the graph in Figure 5.

3. Compared to adults, children experience less "white coat HBP". Once the BP measurement procedure explained and the clear purpose of the study were explained, adherence to the examination increased and the values obtained remained constant at repeated measurements.

4. The same rules applies to DBP - diastolic blood pressure.

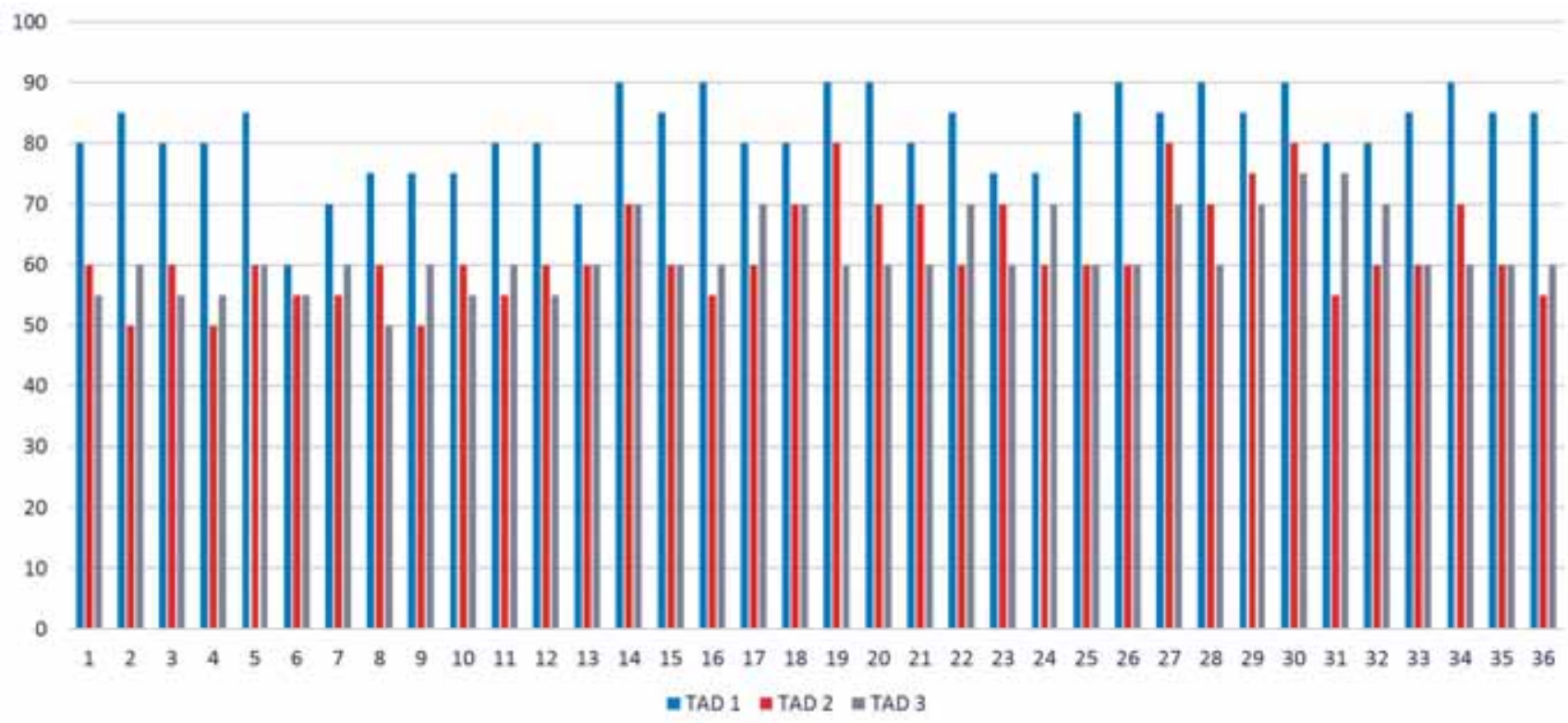

FIGURE 7. DBP - evolution for BP 


\section{Evaluation of risk factors with major im- pact on the monitored community}

The traditional family in our geographical area is often made up of two or even three generations living in the same house or yard. The study aims to highlight the correlation between the existence of intra-family chronic pathology load, the lifestyle and the risk that children and adolescents are exposed to, over time, under the conditions of persistence and persistent action of major risk factors.

Targeted diseases (major chronic family-related diseases):

A. Chronic pathology - HTA, dyslipidaemia, diabetes mellitus, osteo-articular dynamics disorders, cancer, neuropsychiatric disorders.

B. Socio-economic pathology - low level education, parental model, divorce, child whose parents are absent from home for more than 6-12 months / year, domestic violence, bulliying phenomenon (in the school entourage of the child)

Risk factors with major impact on the monitored community identified:

1. Stress / Social Insecurity

2. Obesity

3. HTA and its complications

4. Dyslipidaemia

5. Smoking

6. Pollution

7. Behavior / personality disorder

8. Sleep disorder

9. Nutrition (lack of natural nutrition at the age of infants, currently deficient nutrition)

10. Genetic factors.

The overweight or obese child pursued in the study is often the "product" of his family. (Source: Common parental anamnesis reveals- incorrect nutrition - excessive consumption of lipids, carbohydrates, preparations, excessive care to eat until satiety, low quality of food, fast food, high glycemic index. The Consumer Society, throught commercials from the Media and the phenomenon of "educating the young consumer's tastes" often plays a negative role as "educational way" dedicated to the young consumer Example: comercials for energizers:educate young people to use an unhealthy diet- acidified beverages with artificial sweeteners, other comercials are dedicated to fastfood, and so on

On a predisposal genetic background, modern lifestyle can easily becomes a weapon. The parent or grandparents model is taken over by the child, starting with the unhealthy eating habits of the family and ending with physical inactivity or smoking. Educating the child, we can positively influence the population in care. Family and child information sources are often summed up on TV advertisements, the Internet, so that accessing scientific knowledge, comprehensible and applicable to the whole family, coming from the certified medical staff, the teaching staff, can lead to end to changes in attitudes and behaviors, with positive results over time on the health of the future adult.

\section{Intra-Family Risk Assessment (Intra-Fam-} ily Risk Map - IRM)

Intra-family risk is due to the clustter of chronic non-communicable diseases in a family, in the succession of generations, the outcome of which is the combination of:

- genetic factor

- environmental factos

- lifestyle

Intra-Family Risk Map (IRM) - is a summary of the medical history of the family

According to the Public Health Agency - Canada, due to the social context of globalization, urbanization and the aging of the Globe population, the presence of risk behavior patterns (unhealthy diet, smoking, lack of movement, early consumption and inadequate amounts of alcohol), hypertension, obesity, impaired glucose tolerance, high lipid levels, increased risk of developing, evolution and complications of non-communicable diseases become a reality

Narrower ages are affected, requiring strong, sustainable intervention, especially in the schoolpopulation. Adolescent categories are the most vulnerable but also the most responsive in the positive sense. The basic condition remains receiving the correct information, from the medical staff trained, along with appropriate family support.

\section{Principles of Family Preventive Interven- tions (IPM)}

The Intra-Familial Predictive Model (IPM) has the role to change the lifestyle in the sense of optimizing it. The risk of developing at adult age pathologies that are not a burden only at individual level, but also for the society, because of the disability and social costs

CHECK LIST:

1. Taking and monitoring family health

2. Intrafamily pathology analysis (anamnesis)

3. Intra-Family Risk Assessment (IRA) (genitors and descendants),

4. Elaboration of an intrafamilial predictive model (IPM)

5. Optimizing intrafamiliary lifestyle (counseling and medical professional guidance) 
Estimated results:

Reduce morbidity through chronic diseases at adult age

Quality of individual life (microsystem)

Reducing the social burden of chronic care costs (macrosystem)

Based on these data, an IPM has been developed

A tailor-made Hygiene-Dietary Recommendation Schedule for Children and Families of Origin was developed.

TA (MATA) measurement at home was recommended.

Monitoring - minimum 6 months

In the educational process were involved: the child's family, the child, the medical assistant, the medical doctor, the diabetes doctor, the nutritionist, the ortopaedist.

\section{DISCUSSIONS}

After 6 months of follow-up in the 36 children, the following results were obtained:

Weight reduction by about $8.7 \%$ (limits between $1 \%$ and $13 \%$ relative to initial weight)

Reduction in systolic blood pressure averaged $15 \mathrm{mmHg}$ and $10 \mathrm{mmHg}$ in boys

Daily sports activity - 60 minutes on average than " 0 " before

Reduce computer time with at least 60 minutes daily

Age vaccine coverage (90\% versus $80 \%$ previously)

Professional orientation for children with vertebral static disorder

Average time - 30 minutes a day spent together with the child - "quality family time" (sport, dinner)

In $30 \%$ of the cases, the recommended program by the application of the IPM principles were joined by both parents, in only $25 \%$ of cases only one of the parents. In $45 \%$ of the cases, only the child / adolescent maintained the recommendations without the family joining the program. The best results were obtained where the whole family joined the recommended program

We believe that in order to be able to implement this type of model, the GP needs a broad, interdisciplinary team to allow early detection of these situations, training and time spent with patient and family counselors, human and educational resources to monitor these vulnerable groups of children.

The results are promising, even on a small group of patients. Awareness of the risk of obesity, incorrect nutrition, lack of movement, time spent away from children - in the case of parents (in Romania at this moment - according to UNICEF data, between 57,000-35,000 children in the situation where one or both parents are gone to work outside the country and the child is left in the care of a relative), the risks to which a neglected child is exposed, repression of favored factors that can trigger the occurrence of chronic diseases where there is a genetically predisposing land.

In order to achieve results in the medium and long term, it would be advisable to involve civil society representatives and decision-makers in such projects with patients and medical staff so that medical records can form the basis for developing wider educational programs, targeting vulnerable groups, applicable in the community.

TABLE 1. Sustainable community-oriented solutions

\begin{tabular}{|l|l|l|}
\hline Patient & HCP & $\begin{array}{l}\text { Civil Society/Decision } \\
\text { maker }\end{array}$ \\
\hline $\begin{array}{l}\text { Awareness of the } \\
\text { risk of excessive } \\
\text { weight }\end{array}$ & $\begin{array}{l}\text { Permanent } \\
\text { preven ve attitude }\end{array}$ & $\begin{array}{l}\text { Awareness of the risk } \\
\text { and burden of chronic } \\
\text { diseases }\end{array}$ \\
\hline $\begin{array}{l}\text { Lifelong } \\
\text { educa on } \\
\text { focused on } \\
\text { quality of life }\end{array}$ & $\begin{array}{l}\text { Acquiring the } \\
\text { principles of child } \\
\text { and adult learning }\end{array}$ & $\begin{array}{l}\text { Access to correct } \\
\text { medical informa on }\end{array}$ \\
\hline $\begin{array}{l}\text { Access to } \\
\text { correct medical } \\
\text { informa on, }\end{array}$ & $\begin{array}{l}\text { Medical ac vity } \\
\text { conducted in } \\
\text { accordance with } \\
\text { the principles } \\
\text { of Con nuing } \\
\text { Medical Educa on } \\
\text { (EMc) }\end{array}$ & $\begin{array}{l}\text { Ac ve Responsibility, } \\
\text { Taking responsibility } \\
\text { with Healthcare } \\
\text { Professionals }\end{array}$ \\
\hline $\begin{array}{l}\text { Partnership for } \\
\text { Health Pa ent- } \\
\text { Accountical team }\end{array}$ & $\begin{array}{l}\text { Pa ent-oriented } \\
\text { communica on } \\
\text { training } \\
\text { in favor of Health } \\
\text { Educa on Time }\end{array}$ & $\begin{array}{l}\text { Health Programms } \\
\text { Long-term preven on } \\
\text { policies: Developed by } \\
\text { foreast professional- } \\
\text { interdisciplinary teams } \\
\text { - visionary-sustainable }\end{array}$ \\
\hline
\end{tabular}

\section{CONCLUSIONS}

1. Major-identified risk factors (MRF) common to child: permanent stress, insecure family environment, social and emotional insecurity, bullying, nutrition:

lack of natural food at childbearing age and malnutrition-obesity, HBP, behavioral disorders, sleep disorders, problematic responses to stress, reduced accessibility to educational programs, parental model, children whose parents are abroad.

2. IPM allows for early identification, assessment and intervention focused on major risk factors 
with early childhood action and role in the etiology of future chronic diseases in adulthood

3. IPM allows:

- personalized and family-friendly preventive educational intervention from the youngest ages.

- is an applicable and sustainable model for community and individual level,

- allows the implementation of a personalized, cost-efficient, medium and long-term program

- health education designed to: combat the action of identified risk factors, correct nutrition principles, promote outdoor-sport movement, strong accent on optimal level mental health status, suitable professional orientation, family balance

\section{PROSPECTIVE STUDIES}

In order to obtain statistically significant results, it would be advisable to extend the study to a larger number of children and families with chronic noncommunicable diseases and a monitoring period longer than 6 months.

The number of children enrolled in the study was reduced, the selective criteria for inclusion in the study being the presence of overweight-obesity and the agglomeration of chronic diseases within the child family.

Conflict of interest: none declared Financial support: none declared

\section{REFERENCES}

1. Guideline assessing and managing children at primary health-care facilities to prevent overweight and obesity în the context of the double burden of malnutrition updates for the integrated management of childhood illness (imci) who. double burden of malnutrition (http:// www.who.int/features/qa/malnutrition/en/).https://www.who.int/ nutrition/publications/guidelines/children-primaryhealthcare-obesity$\mathrm{dbm} / \mathrm{en} /$, accesat 29 noi 2018

2. Analiză de situaţie Ziua Europeană împotriva obezității http://insp.gov. ro/sites/cnepss/wp-content/uploads/2016/05/analiză-de-situație-ptzeio-2016.pdf, accesat 29 noi 2018

3. WHO european ministerial conference on counteracting obesity conference report http://www.euro.who.int/_data/assets/pdf_ file/0006/96459/e90143.pdf

4. State of health în the EU România profilul sănătătiii în 2017,pag 5 https://ec.europa.eu/health/sites/health/files/state/docs/chp_romania_ romanian.pdf

5. Malnutrition http://www.who.int/mediacentre/factsheets/malnutrition/ en/ 2018

6. http://www.who.int/childgrowth/publications/en/ accesat noi 2018

7. Clinical growth charts http://www.cdc.gov/growthcharts/ noi 2018

8. http://www.cdt-babeș.ro/articole/indicele-de-masă-corporală-imc.php

9. http://www.insp.gov.ro/cnepss/wp-content/uploads/2010/12/ evaluarea-nivelului-de-dezvoltare-fizică-și-a-stării-de-sănătate-2011. pdf

10. Endorsement of the new who growth standards for infants and young children by the european childhood obesity group (ecog) http://www. who.int/childgrowth/endorsement_ecog.pdf?uă=1

11. Evaluarea stării de nutriţie a copiilor din ciclul primar conform metodologiei OMS prin participarea la Proiectul"European childhood obesity surveillance inițiative (cosi)". Raport Naţional România 2017 http://insp.gov.ro/sites/cnepss/wp-content/uploads/2018/06/ raport-național-cosi-2017.pdf accesat 29 noi 2018

12. Calculate Your Body Mass Index https://www.nhlbi.nih.gov/health/ educational/lose_wt/index.htm 